\title{
TADLIS MERUSAK PRINSIP 'ANTARADHIN DALAM TRANSAKSI
}

\author{
Taufiq \\ Jurusan Syariah STAIN Malikussaleh Lhokseumawe \\ Jl. Banda Aceh-Medan Km. 275 No. 1 Buket Rata-Alue Awe Lhokseumawe \\ e-mail: taufiqmahmud1979@gmail.com
}

\begin{abstract}
One of the principles emphasized in transaction is willingness (antaradhin). The principle ensures that all parties involved in transaction get satisfaction. This means none of the parties get benefit while the other suffers from loss as the consequences of the transaction. The jumbur ulama agree that the principle is implementing in the form of ijab and qabul. The principle of antaradbin is achieved through sharing the same amount necessary information (complete information) between two parties. However, not all of transactions end in satisfaction. This is due to the fact that one of the parties tries to bide necessary information from the other one. That means one party is deceived by the other. This kind of behavior is known as cheating (tadlis). Tadlis may appear in the form of hiding real or true conditions of the trading goods, increasing the price and so forth. These may take hiding information on the quality, quantity, time, and price of the goods. This paper therefore aims at discussing in more detailed Islamic perceptions toward antaradhin (willingness), tadlis (deception) and how the habit of committing to tadlis destroys the principles of antaradhin in the process transaction.
\end{abstract}

Kata kunci: tadlis, 'antaradhin, transaksi

\section{PENDAHULUAN}

$I$ bnu Khaldun menyebutkan bahwa manusia merupakan makhluk yang bermasyarakat (hayawan al ijtima'i), mulai kelompok kecil, keluarga sampai dengan skala besar sekalipun dan manusia juga memiliki karakter al insan madaniyyun bil atba'i yaitu makhluk sosial yang membutuhkan orang lain dalam memenuhi kebutuhan hidup. (Ibnu Khaldun, t.th.: 33-34). Dalam konteks syariat, interaksi pemenuhan kebutuhan hidup disebut dengan muamalah. Dalam konteks ini, interaksi yang terjadi memiliki batasan-batasan yang harus dijaga. Terutama dalam persoalan transaksi. Prinsip yang sangat mendasar dalam hal pemenuhan kebutuhan antar para pihak adalah adanya keridaan baik secara lahir maupun batin dan syariat memberikan batasan-batasan.

Permasalahan keridaan bukan hanya pada perilaku yang terlihat, juga pada maksud yang tersirat dalam akad yang akan berlangsung. Kesempurnaan sikap belum tentu menunjukkan kerelaan terhadap sebuah perikatan atau perjanjian yang disepakati. Tapi lebih dari itu adalah tujuan yang tersirat dari para pihak pun menentukan bentuk keridaan. Sebagaimana disebutkan dalam kaidah berikut:

$$
\text { العبرة في العقود بالمقاصد والمعاني لا بالألفاظ والمباني }
$$

Inti akad berdasarkan maksud dan makna akad, bukan berdasarkan lafadz dan kalimat.

Karena dalam setiap transaksi harus memperhatikan keseimbangan dankeadilan yang akan terjadi kepada para pihak, terutama 
resiko yang ditimbulkan oleh salah satu pihak yang diakibatkan oleh ketidakridaan yang ditimbulkan oleh pihak yang lain. Termasuk dalam masalah mencari keuntungan. Rasulullah Saw tidak melarang seseorang mencari keuntungan, namun harus memperhatikan juga nilai resiko yang ditimbulkan dari pekerjaan tersebut. Rasulullah Saw bersabda:

$$
\text { وَلاَ رِبْحُ مَا لَهُ تَضْنَنْ }
$$

Tidak boleh mendapat keuntungan tanpa menanggung resiko kerugian." (HR. Ahmad 6671, Abu Daud 3506, Turmudzi 1279 dan dihasankan Syuaib al-Arnauth, Hadis bersumber dari Itab bin Usaid)

Oleh sebab itu keridaan dalam melakukan suatu transaksi harus jelas dan tidak boleh menyembunyikan apapun kekurangan dari transaksi yang dilakukan. Karena akan menimbulkan kerugian dan dianggap sebuah pekerjaan yang batil (Q.S. an-Nisa [4]: 29). Salah satu dari bentuk yang dapat merusak keridaan adalah adanya informasi yang tersembunyi dan sengaja disembunyikan, yang pada zahirnya tidak tampak ketika terjadi transaksi, yang diistilahkan dengan tadlis.

\section{MAKNA 'ANTARADHIN}

Bila dilihat dari segi arti harfiah 'antaradhin minkum, bahwa kata تراض memiliki mamiliki wazan mufaa'ala, yang artinya bahwa kalimat tersebut menunjukkan adanya hubungan timbal balik antara satu dengan lainnya. Kata dasar dari تراض adalah رضى yang artinya rela/suka.
Malik bin Anas, Abu Hanifah, Abu Yusuf berpendapat, bahwa makna antaradhin minkum tersebut adalah keridaan dalam jual beli terletak pada akad, penjual menyerahkan barang dan pembeli menyerahkan uangnya, baik ada khiyar atau tidak setelah atau masih dalam transaksi. Dengan alasan karena jual beli terjadi dengan lisan atau ucapan. Golongan ini berpegang pada makna Hadis "Jual beli dengan khiyar selama belum berpisah" (البيعان بالخيار مالم يتفرقا). Dalam artian selama belum berpisah maka keridaan itu bisa dinyatakan dengan ucapan.

Kata 'antaradhin dapat ditemukan dalam Alquran surat an-Nisa' ayat 29:

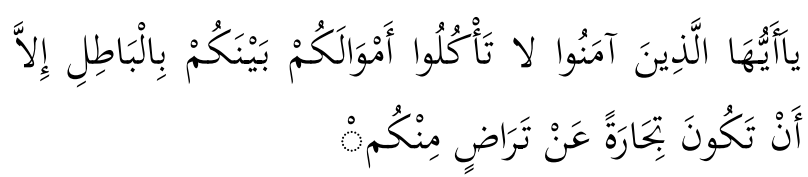

Hai orang-orang yang beriman, janganlah kamu saling memakan harta sesamamu dengan jalan yang batil, kecuali dengan jalan perniagaan yang berlaku dengan suka sama suka diantara kamu. (Q.S. an-Nisa' [4]: 29).

Ayat ini mengandung makna yang sangat umum dan luas ketika dijabarkan dalam persoalan muamalah. Dan dari ayat ini juga melahirkan beragam penafsiran yang berkaitan dengan hukum-hukum ekonomi dalam Islam yang terperinci (tafsily).

Al-Maraghi menjelaskan bahwa ayat tersebut merupakan kaidah umum tentang transaksi dalam persoalan harta yang merupakan upaya pembersih jiwa dalam mengumpulkan harta yang dicintai, dan bahagian dari ketidakridaan adalah timbulnya unsur penipuan, pendustaan, dan pemalsuan adalah hal 
yang haram yang sangat berlawanan dengan keridaan (al-Maraghi, 1986: 10).

Ibnu Katsir menafsirkan kata 'antaradhin ayat 29 dari surah an-Nisa' tersebut bahwa, janganlah kalian menjalankan usaha yang menyebabkan perbuatan yang diharamkan tetapi berniagalah menurut aturan syariat yaitu perniagaan yang dilakukan suka sama suka ('antaradhin) di antara pihak pembeli dan penjual. Dan menganjurkan untuk mencari keuntungan yang diakui oleh syariat (Ibnu Kasir, t.th.: 558).

Wahbah az-Zuhaily menafsirkan kata 'antaradhin pada surah an-Nisa' ayat 29 tersebut:

$$
\begin{aligned}
& \text { التراضي : الاتفاق المتبادل بين المتبا يعين دون غش } \\
& \text { ولاكتمان عيب ولامقامرةولامراباة }
\end{aligned}
$$

Keridaan adalah kesepakatan yang muncul dari kedua belah pihak (pihak yang berakad jual beli) tanpa ada penipuan, penyembunyian aib, unsur perjudian, dan riba. (Az-Zuhaili, $1417 \mathrm{H:}: 84$ )

Islam mensyaratkan setiap transaksi perdagangan harus berdasarkan kerelaan kedua belah pihak (penjual dan pembeli) yang terlibat. Transaksi tidak sah dengan ketidakrelaan salah satu atau kedua belah pihak. Karena keridaan dalam bertransaksi adalah merupakan prinsip. Oleh karena itu transaksi barulah sah apabila didasari oleh kedua belah pihak (A. Djazuli, 2006: 130). Sebuahkaidah fighiyah menyebutkan:

الأصل في العقد رض المتعاقدين ونتيجته ماإلتزماه بلا تعا

Hukum asal dari transaksi adalah keridaan kedua belah pihak yang berakad, hasilnya adalah berlaku sahnya yang diakadkan.
Wahbah az-Zuhaili juga menegaskan bahwa tidak semua bentuk saling rida diakui oleh syara', namun yang diakui adalah keridaan yang berada dalam batasbatas syara'. Dan mayoritas ulama figh bersepakat, dilandasi dari pesan surat anNisa' tersebut bahwa keridaan merupakan tegaknya sebuah akad (Dimyaudin Dimyaini, 2010: 60).

Dalam Hadis Rasulullah Saw dapat ditemukan beberapa kata 'antaradhin dalam beberapa Hadis beliau:

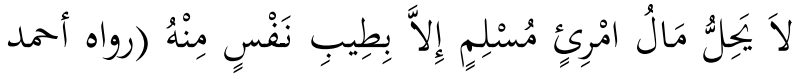

$$
\begin{aligned}
& \text { والدارقطني والبيهقي، وصححه الحافظ والألباني) }
\end{aligned}
$$

Tidaklah halal harta seorang muslim kecuali dengan dasar kerelaan dari-nya. (Riwayat Ahmad, ad Daraquthny, Al Baihaqy dan dinyatakan sebagai Hadis shahih oleh Al Hafizh Ibnu Hajar dan Al Albany).

Lebih khusus lagi Hadis Rasulullah Saw yang diriwayatkan oleh Ibnu Majah menyebutkan kata 'antaradhin berkaitan dengan jual beli:

$$
\begin{aligned}
& \text { عن أبى سعيد الخدرى رضى الله عنه قال رسول الله صلى }
\end{aligned}
$$

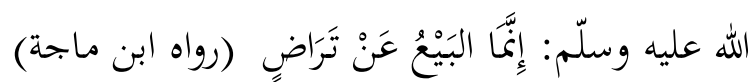

Sesungguhnya perniagaan itu hanyalah perniagaan yang didasari oleh rasa suka sama suka. (Ibnu Majah, 2005: 277)

$$
\begin{aligned}
& \text { عن أبى هريرة رضى الله عنه قال رسول الله صلى الله عليه }
\end{aligned}
$$

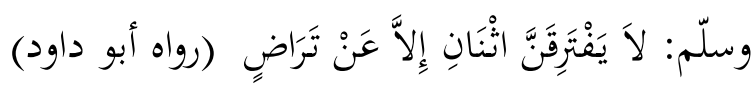


Berdasarkan persyaratan ini, para ulama menegaskan bahwa tidak sah akad penjualan yang dilakukan oleh orang terpaksa, karena akad tersebut tidak didasari oleh asas suka sama suka. Sehingga dengan prinsip ini tidak akan ada pihak-pihak yang akan terzalimi akibat dari ketidakridaannya.

\section{TADLIS DALAM 'ANTARADHIN}

Adiwarman A. Karim menyebutkan bahwa wujud dari sikap 'antaradhin adalah para pihak yang berakad harus memiliki informasi yang sama (complete informasi). Tidak boleh ada sikap merasa dicurangi karena salah satu pihak mempunyai informasi dengan tidak memberitahukan informasi yang dia ketahui kepada pihak lain. (Adiwarman A. Karim, 2010: 31).

Dilihat dari aspek pengertian tentang 'antaradhin (sebagaimana dijelaskan di atas), bahwa salah satu bahagian dari perilaku yang menimbulkan ketidakridaan dalam perdagangan adalah lahirnya perilaku menyembunyikan informasi sebenarnya berkaitan dengan akad yang dilakukan, atau yang dalam istilah figh disebut dengan penipuan (tadlis / تدليس) terhadap para pihak yang berakad. Dalam hal ini para pihak dalam perdagangan atau jual beli.

Secara bahasa تدليس berasal dari kata

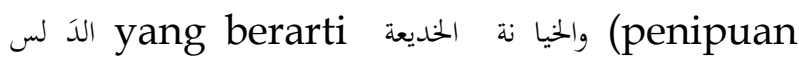
dan khianat). Seseorang dikatakan telah berbuat tadlis dalam jual beli bila tidak menjelaskan kekurangan objek barang yang ditransaksikan. (Ali Ahmad Mar'i. dkk, 1997: 429).

secara bahasa sebagaimana disebutkan oleh Al Jauhary dan Ibnu
Mandhur adalah (menyembunyikan aib), sedangkan makna تدليس dalam jual beli adalah menyembunyikan cacat barang pada pembeli (Ibnu Mandhur, t.th.: 930)

Hal ini sesuai dengan Hadis Rasulullah Saw yang melarang melakukan penipuan dengan berbagai alasan apapun:

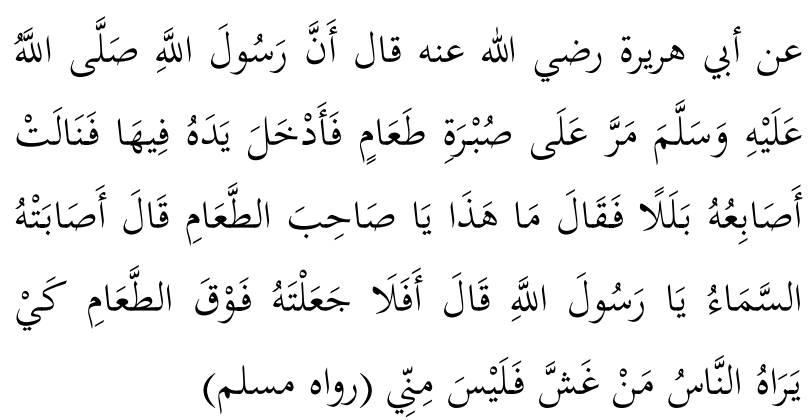

Dari Abi Hurairah $R a$ berkata: bahwa Rasulullah Saw pernah melewati setumpuk makanan, lalu beliau memasukkan tangannya ke dalamnya, kemudian tangan beliau menyentuh sesuatu yang basah. Maka beliaupun bertanya, "Apa ini wahai pemilik makanan?" Dia menjawab, "Makanan tersebut terkena air hujan wahai Rasulullah." Beliau bersabda, "Mengapa kamu tidak meletakkannya di bagian atas agar manusia dapat melihatnya?! Barangsiapa yang menipu maka dia bukan dari golonganku." (Muslim, 2001: 95)

Imam Nawawi menjelaskan bahwa kata فَلَئنسن مِنِ adalah tidak termasuk dari golongan yang tidak berjalan atas petunjuk syara' dan mengikuti ilmu, amal, dan petunjuk syara' yang benar. Hadis tersebut merupakan dalil atas keharaman melakukan penipuan dan secara syara' hukum keharamannya telah menjadi ijma' ulama serta secara logika pun pelakunya sangat tercela (Asy-Syaukani, 2000: 222).

Dalam Hadis-hadis Rasulullah Saw istilah penipuan sering disebutkan dengan kata غش, yang pada dasarnya 
sama dengan istilah تدليس, para fuqaha membatasi تدليس pada saat atau sedang terjadi transaksi. Sedangkan gahisy lebih umum, prakteknya bisa terjadi sebagaimana pada tadlis atau penipuan setelah terjadinya transaksi (Khatib AsySyarbaini, t.th.: 65). Dan itu hanya sebatas pada istilah saja. Makna istilah dalam kaidah figh adalah:

$$
\text { إصطلاح : إتفا ق طا ئفة ما على شئ ما }
$$

Istilah dalam bahasa Arab adalah إصطلاح atau tapi ulama sering menggunakan مصطلح dari pada إصطلاح

الدلسة juga berasal dari kata تدليس semakna dengan الظلمة (kegelapan), dalam keadaan ini seolah-olah penjual telah menjadikan pembeli dalam kegelapan maknawi yaitu penjual tidak memberitahu hakikat barang yang sebenarnya.

Sebahagian fuqaha hadis mendefiniskan tadlis adalah setiap usaha menyembunyikan aib pada barang yang diakadkan atau barang yang diperjualbelikan supaya tampak bagus dan berbeda dengan keadaan yang sebenarnya sehingga barang dapat dijual dengan harga tinggi. (Muhammad Yusuf Musa, t.t.: 403 dan Yusuf Qasim, 1997: 304)

Beragam definisi mengenai tadlis yang diberikan oleh para fuqaha dengan maksudnya sama yaitu menyembunyikan aib pada barang sehingga tidak diketahui oleh pembeli dan mengakibatkan nilai suatu barang berkurang dan harga terhadap barang yang dijual dapat dinaikkan atau sebagaimana harga pasaran. (Ali Ahmad Mar'i. dkk, 1997: 431)

Selain istilah تدليس sebahagian fuqaha yang juga menggunakan istilah غبن ghaban yaitu jual beli yang tidak adanya kesesuaian antara nilai suatu barang dengan harga yang seharusnya. Ketidakseimbangan nilai barang dengan harga yang seharusnya bukan hanya pada adanya aib tapi memang nilai barang tersebut rendah tapi para pedagang menjualnya dengan harga tinggi sebagaimana harga pasar. Perbedaannya yang mendasar adalah tadlis lebih pada menyembunyikan aib sedangkan ghaban lebih pada nilai barang tersebut, yang pada dasarnya harganya rendah namun pedagang berusaha menjual dengan harga yang setinggi-tingginya. Dilihat korelasi antara tadlis dengan ghaban adalah bahwa ghaban merupakan hasil dari perilaku tadlis. Tidak mungkin pedagang melakukan ghaban tanpa adanya unsur tadlis di dalamnya.

Bila diurutkan secara praktik maka ghassya lebih umum dari tadlis dan ghaban merupakan bahagian dari tadlis. Namun perbedaan penyebutan tersebut menurut penulis tidak perlu dipermasalahkan dan dipertentangkan sebagaimana kaidah:

$$
\text { لامشا حة في المصطلح }
$$

Tidak boleh dipertentangkan dalam hal penggunaan istilah

Maksud dari kaidah di atas yaitu seperti adanya dua ulama atau lebih menggunakan satu istilah untuk dua makna yang berbeda.

Muhammad Abu Zahrah menyebutkan bahwa tadlis merupakan usaha menyembunyikan aib yang terdapat pada barang dari pembeli. Transaksi terhadap barang tersebut yang jelas ada aibnya tidak dibarengi dengan penjelasan. Dan syara' tidak mengakui transaksi seperti itu baik dengan menipu atau menutup aib yang ada pada objek akad. (Muhammad Abu Zahrah, 1996: 442) 
Kejujuran adalah salah satu pilar utama dalam perdagangan, karena Allah mengancam orang yang tidak jujur dan tidak adil dengan ancaman siksa yang pedih:

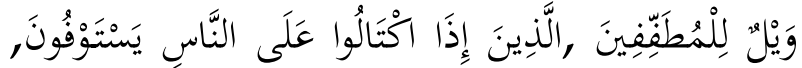

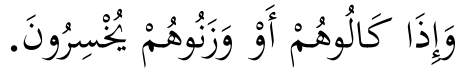

Kecelakaan besarlah bagi orang-orang yang curang. (Yaitu) orang-orang yang apabila menerima takaran dari orang lain mereka minta dipenuhi. Dan apabila mereka menakar atau menimbang untuk orang lain, mereka mengurangi" (Q.S. al-Muthaffifin [83]: 1-3)

Dalam sebuah Hadis yang diriwayatkan oleh Rifa'ah dinyatakan Hadis sahih oleh Hakim, Nabi Saw bersabda:

$$
\begin{aligned}
& \text { عن رفاعة بن رافع ان النبي صلي الله عليه وسلم: سئل } \\
& \text { أي الكسب أطيب ؟ عمل الرجل بيده وكل بيع مبرور) } \\
& \text { رواه البزار وصححه الحاكم) }
\end{aligned}
$$

Diriwayatkan Rifa'ah bin Rafi': Suatu ketika (seseorang) bertanya kepada Nabi Saw: pekerjaan apakah yang terbaik? Nabi Saw menjawab: "Pekerjaan seseorang dengan tangannya dan setiap jual beli yang sah." (Al-Bazzar, 1998: 183)

Ibnu Hajar al-Asqalani memberikan keterangan dalam kitab Subulus Salam, bahwa maksud dari jual beli yang sah dalam Hadis tersebut adalah yang terbebas dari sumpah palsu agar barangnya laku maupun penipuan lainnya, dan yang dimaksud dengan pekerjaan terbaik adalah yang paling halal dan paling berkah. Sedangkan menurut Sayyid Sabiq, (Sayyid Sabiq, 2000: 45), jual beli yang sah dalam Hadis tersebut adalah yang tidak mengandung penipuan dan pengkhianatan.

Rasulullah Saw menganjurkan agar pedagang tetap menjaga persaudaraannya selaku muslim di saat melakukan jual beli yaitu dengan menjelaskan kondisi barang dalam artian memberikan informasi sebenarnya tentang kondisi dengan tidak menyembunyikan aib.:

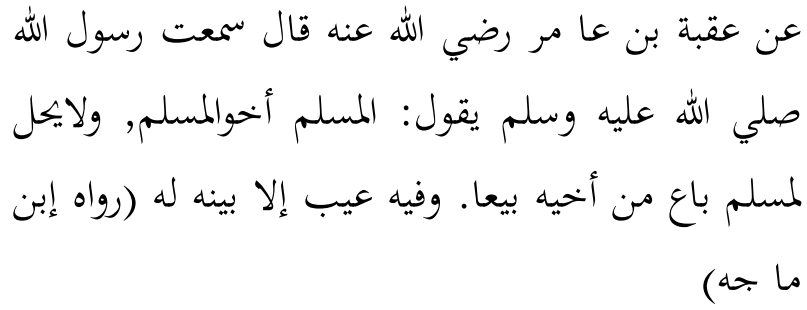

Dari 'Aqibah bin Amir Ra. Bersabda Rasulullah Saw seorang muslim adalah saudara muslim lainnya, tidak halal bagi seorang muslim menjual barang kepada saudaranya yang di dalamnya ada cacat, kecuali ia menerangkan cacat tersebut. (Ibnu Majah, 2005: 299)

Ali Ahmad Mar'i, Muhammad Hamli Isa dan Salim Ahmad Muhammad Salamah dalam Buhusu fi Fiqhi al-Mu'amalat Dirasah Muqarranah, memberikan pandangannya bahwa tadlis tidak sebatas menutupi cacat suatu barang, akan tetapi seluruh kegiatan yang semestinya berkurang nilainya namun dijual melebihi standar harga seharusnya. (Ali Ahmad Mar'i. dkk, 1997: 432).

Bahkan Rasulullah Saw mengancam para pedagang yang melakukan penipuan terhadap konsumen:

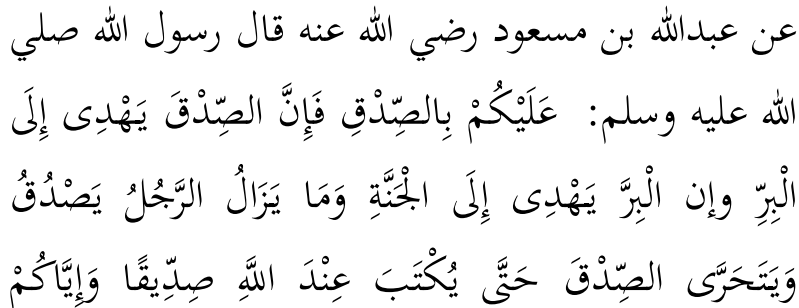


وَالْكَخِبَب فَإِنَّ الْكَذِبَ يَهْهِى إِلَى الْفُجُورِ وَإِنَّ الْفُجُورَ

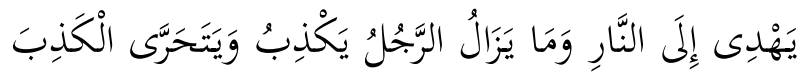

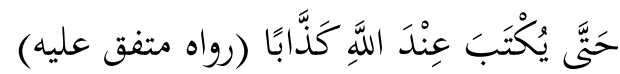

Hendaknya kalian senantiasa jujur, karena kejujuran membawamu kepada kebaikan. Sedangkan kebaikan membawamu ke surga. Tidaklah seseorang senantiasa berbuat kejujuran dan berusaha berbuat jujur, hingga suatu saat nanti ia dituliskan disisi Allah sebagai orang yang (shiddiq) jujur. Dan waspadalah kalian dari perbuatan dusta, karena kedustaan menghantarkanmu kepada kejahatan. Sedangkan kejahatan menjerumuskanmu ke dalam neraka. Dan tidaklah seseorang senantiasa berbuat dusta dan berupaya untuk berdusta hingga akhirnya ia ditulis di sisi Allah sebagai pendusta. (Muttafaqun 'alaih) (Muslim, 2001: 150).

Bukan hanya sebatas memberikan sanksi kepada pedagang yang melakukan penipuan, namun Islam juga memberi apresiasi yang sangat tinggi kepada pelaku perdagangan yang jujur sebagaimana sabda Nabi Saw:

$$
\begin{aligned}
& \text { عن ابن عمرضي الله عنهما قال:قال رسول الله صلى الله }
\end{aligned}
$$

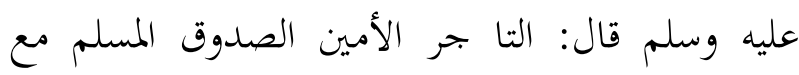

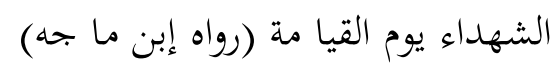

Diriwayatkan dari Ibn 'Umar Ra, bahwasanya Rasulullah Saw telah bersabda: "Pedagang yang jujur, terpercaya, dan beragama Islam ditempatkan bersama para syuhada pada hari kiamat."(Ibnu Majah, 2005: 261)

Di Hadis yang lain disebutkan:
عن جا بربن عبدالله رضي الله عنه قال النبي صلي الله

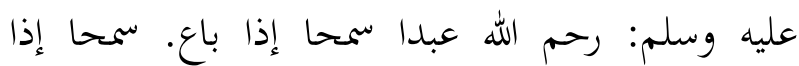
اشترى. سمحا إذا اقتضي (رواه إبن ما جهد)

Dari Jabir bin Abdullah, Nabi Saw bersabda: "Allah memberikan rahmat-Nya pada setiap orang yang bersikap baik ketika menjual, membeli, menunaikan hutang, dan membuat suatu pernyataan" (Ibnu Majah, 2005: 284)

Bila diamati perilaku pedagang yang melakukan praktek perdagangannya dengan tidak berprinsip pada etika kejujuran, maka dapat digolongkan dalam beberapa bentuk penipuan (tadlis) yang dilakukan oleh para pedagang, sebagaimana yang disebutkan oleh Adiwarman A. Karim (2010: 31) yaitu penipuan atau tadlis yang terjadi pada:

1. Kualitas

2. Kuantitas

3. Waktu

4. Harga

Namun Adiwarman A. Karim tidak menyebutkan bahwa ada perilaku pedagang yang terkadang menyembunyikan informasi keberadaan tempat perdagangan yang menyedia jasa atau barang yang dibutuhkan oleh konsumen.

Perilaku tersebut biasanya ketika konsumen atau pembeli menanyakan tempat lain yang dapat ditemukan barang yang dibutuhkan. Pedagang berkelit dengan tidak menyebutkan tempat atau menunjukkan bukan tempat yang dimaksud dengan beragam alasan.

Jadi menurut penulis selain tadlis dalam bentuk kualitas, kuantitas, waktu, dan harga, juga tidak memberitahukan tempat yang diinginkan pembeli menjadi bahagian dari pembahagian tadlis. 
Selain tadlis, juga adanya perilaku sumpah palsu sebagai bentuk meyakinkan pembeli terhadap barang yang dijajakan. Sumpah palsu lahir dari perilaku tadlis karena ada sesuatu informasi yang disembunyikan maka pedagang akan berusaha meyakinkan pembeli. Namun tidak semuanya karena adanya unsur tadlis terkadang memang informasi yang diberikan sesuai dengan kondisi objek transaksi.

Pada kebiasaannya sumpah palsu ini banyak dilakukan para pedagang dengan tujuan untuk melariskan dagangannya. Sumpah palsu ini meliputi kebohongan besarnya modal dan keuntungan, kondisi barang dagangan, dan yang lainnya.

Meskipun sumpah palsu itu terkadang dapat menjadikan larisnya perniagaan serta memuluskan perdagangan karena dapat meyakinkan pembeli, namun dalam konteks ekonomi Islam keberkahan akan terhapus dari hasil perniagaan dengan cara seperti itu.

عن أبى هريرة رضي الله عنه سمعت رسول الله صلي الله

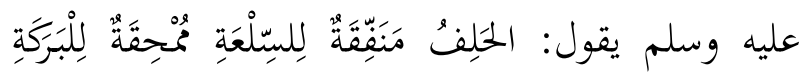

$$
\text { (رواه البخارى ) }
$$

Sumpah palsu itu akan menjadikan barang dagangan menjadi laris manis, (akan tetapi) menghapuskan keberkahan. (Bukhari, 1407: 369)

Sumpah dalam jual beli itu secara mutlak makruh, baik pelakunya seorang pendusta maupun orang yang jujur. Jika pelakunya seorang yang suka berdusta dalam sumpahnya, maka sumpahnya menjadi makruh yang mengarah kepada haram, dosanya lebih besar dan azabnya sangat pedih, dan itulah yang disebut dengan sumpah dusta.
Sumpah bukan hanya berkenaan dengan kondisi objek barang juga pada persoalan harga yang ditawarkan, dengan cara bersumpah bahwa harga yang ditawarkan merupakan harga yang terendah. Rasulullah bersabda:

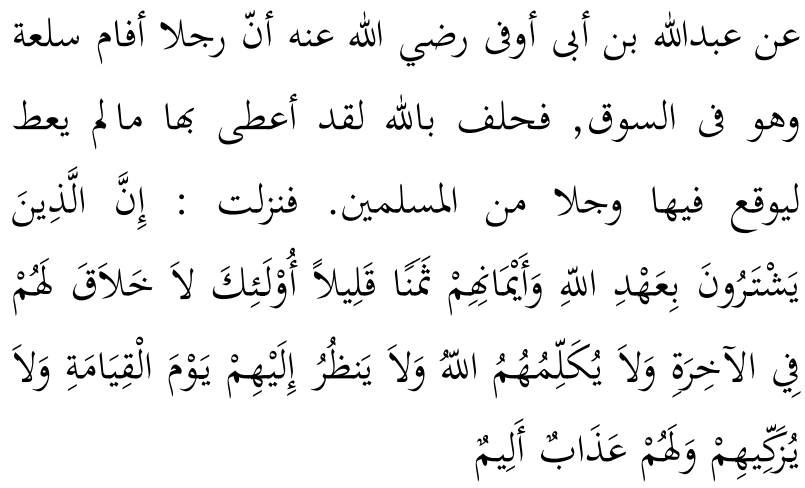

Dari Abdullah bin Abi Aufa Radhiyallahu 'anhu, bahwasanya ada seseorang yang menawarkan suatu barang di pasar, lalu dia bersumpah atas nama Allah bahwa dia telah memberikan harga yang paling rendah yang belum pernah diberikan, agar ada seorang muslim yang terjebak, lalu turunlah ayat.

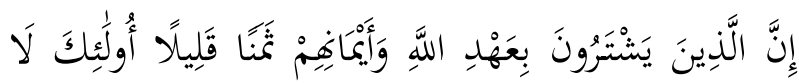

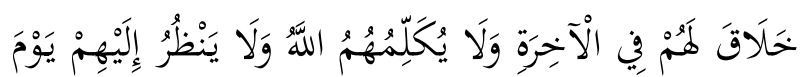

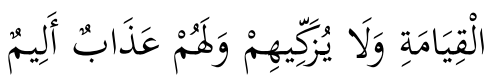

Sesungguhnya orang-orang yang menukar janji (nya dengan) Allah dan sumpahsumpah mereka dengan harga yang sedikit, mereka itu tidak mendapat bahagian (pahala) di akhirat, dan Allah tidak akan berbicara pada mereka dan tidak (pula) akan melihat kepada mereka pada hari Kiamat dan tidak (pula) akan menyucikan mereka. Bagi mereka Azab yang pedih (Q.S. Ali-Imran [3]: 77)

Juga didasarkan pada keumuman firman Allah Swt dalam surah al-Maidah ayat 89 : 


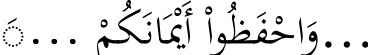

...Dan jagalah sumpah kalian... (Q.S. alMaidah [5]: 89)

Serta surah al-Baqarah ayat 224:

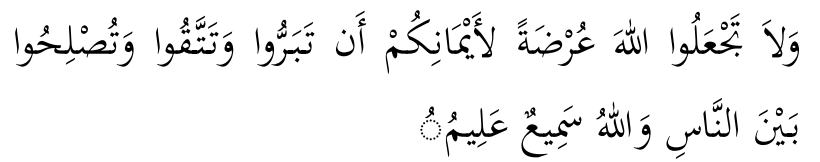

Janganlah kamu jadikan (nama) Allah dalam sumpahmu sebagai penghalang untuk berbuat kebajikan, bertakwa, dan mengadakan ishlah di antara manusia. Dan Allah Maha Mendengar lagi Maha Mengetahui. (Q.S. al-Baqarah [2]: 224)

Dan dalam Hadis yang lain yang diriwayatkan oleh Bukhari dan Muslim di dalam kitab Shahih keduanya:

$$
\begin{aligned}
& \text { عن أبى هريرة رضي الله عنه رضي الله عنه قال: قال } \\
& \text { رسول الله صلى الله عليه وسلم: ثلاثة لا يكلّمهم الله } \\
& \text { عزوجلّ يوم القيامة, ولا ينظر إليهم, ولايزّيهم ولهم } \\
& \text { عذاب أليم: رجل على فضل ماء بالفلاقيمنعه ابن } \\
& \text { السبيل, رجل بايع رجلاسلعةبعدالعصر فحلف بالله } \\
& \text { لأخذها بكذاوكذا. فصدّقه وهوعلى غير ذالك. و رجل } \\
& \text { بايع إماما لايبا يعه إلاّ لدّنيا فإن أعطاه منها وفى له, وإن } \\
& \text { لم يعطه منها لم يف له (رواه إبن ماجه) }
\end{aligned}
$$

Dari Abu Hurairah Radhiyallahu 'anhu, dia bercerita, Rasulullah Saw telah bersabda: Tiga golongan yang tidak akan diajak bicara oleh Allah, tidak juga dilihat dan disucikan-Nya, dan bagi mereka azab yang sangat pedih; Seseorang yang mempunyai kelebihan air di sebuah jalanan, dimana dia menghalangi para pejalan dari air tersebut, lalu seseorang membai'at seseorang -dalam sebuah riwayat: seorang imam- yang dia tidak membai'atnya melainkan untuk kepentingan dunia, yang jika orang dibai'atnya itu memberi apa yang dia inginkan, maka dia akan mentaatinya dan jika tidak maka dia tidak mentaatinya, serta seseorang yang menawar barang dagangan orang lain setelah Ashar, lalu dia (penjual, -ed) bersumpah dengan menggunakan nama Allah bahwa dia benar-benar telah memperoleh barang tersebut sekian dan sekian, lalu diambillah oleh orang itu. (Ibnu Majah, 2005: 286)

Prinsip-prinsip tersebut di atas adalah merupakan perilaku yang melanggar prinsip kerelaan. Sifat kerelaan yang ditunjukkan di saat transaksi merupakan bentuk kerelaan sementara, karena yang ditipu dalam hal ini pembeli tidak mengetahui kalau dirinya ditipu oleh pedagang. Sehingga di saat pembeli mengetahui bahwa dirinya telah ditipu, maka ia tidak akan rela dengan perlakuan tersebut.

\section{PENUTUP}

Prinsip keridaan dalam sebuah transaksi tidak hanya sebatas sikap yang ditimbulkan dari para pihak, namun sikap menyembunyikan informasi pun menjadi penghalang dalam transaksi. Perbuatan menyembunyikan informasi yang dilakukan oleh salah satu pihak yang melakukan transaksi dikenal dengan istilah tadlis. Tadlis dapat berupa dalam bentuk kualitas, kuantitas, waktu maupun harga. Dan tadlis ini merupakan bentuk dari sikap khianat kepada orang lain. Syariat sangat memperhatikan sifat-sifat yang tidak terpuji dalam melakukan hablumminannas, agar keberlangsungan kehidupan tetap terjadi. 


\section{DAFTAR KEPUSTAKAAN}

A. Karim, Adiwarman. 2010. Bank Islam: Analisis Figh dan Keuangan. Edisi IV. Jakarta: Rajawali Pers. Cet. VII

Ad-Dimsyiqy, Imaduddin Ismail Bin Kasir. t.th.. Tafsir Ibnu Kasir. Malawi: Darut Taqwa

Al Jauhari. t.th. As-Shihah Juz III

Al-Bazzar. 1409 H/1998 M. Musnad AlBazzar. Juz. 9. Beirut: Muassasah Ulumul Qur'an. Cet.I

Al-Maraghi, Ahmad Musththafa. 1986. Tafsir al-Maraghi, (terj.). Juz. V. Semarang: Toha Putra

Asy-Syarbaini, Khatib. t.th. Mughni alMuhtaj. Juz. II. Al-Maktabah atTafiqiyah

Asy-Syaukani. 1421 H/ 2000 M. Nailul Authar. Juz. V. Kairo: Dar Hadis

Az-Zuhaily, Wahbah. 1417 H. Tafsir alWajiz wa Mu'jam Ma'ani alquran al'Aziz. Cet. I. Damsyik: Darul Fikri

Bukhari, Imam. 1407 H. Fathu al-Barri bi Syarhi Shahih Bukhari. Juz.4. Kairo: al-Maktabah as-Salafiah. Cet.III

Daud, Abu. 1422 H/2001 M. Sunan Abu Daud. Juz.6. Kairo: Dar Hadis.

Dimyaini, Dimyaudin. 2010. Fiqh Muamalah Yogyakarta: Pustaka Pelajar

Djazuli, Ahmad. 2006. Kaidah-kaidah Fikih: Kaidah-kaidah Hukum Islam dalam Menyelesaikan Masalah-masalah yang Praktis. Jakarta: Pranata Media
Hasyiyah ar-Raudhu al-Murbi' Syarah Zad al-Mustaqni'. Juz IV.

Khaldun, Ibnu. t.th. Muqaddimah. Beirut: Dar al Fikr

Majah, Ibnu. 1426 H/2005M. Sunan Ibnu Majah. Juz.II. Kairo: Dar Hadis

Mandhur, Ibnu. t.th. Lisan al 'Arab. Mesir: Dar al Hadis

Mar'i, Ali Ahmad dkk. 1418 H / 1997 M. Buhutsu fi Figh al-Mu'amalat Dirasah Muqaranah. Kairo: Fakultas Syariah wa Qanun Universitas Al-Azhar

Musa, Muhammad Yusuf. t.th. Al-Figh AlIslamy

Muslim. 1422 H/2001 M. Shahih Muslim bi Syarah Nawawi. Juz.XVI. Dar Dakwah Islamiyah. Cet. I 1422 H/2001 M. Shahih Muslim. Juz.2. Dar Da'wah Islamiyah. Cet.I

Qasim, Yusuf. 1979. Mabadi' Al-Figh AlIslamy. Kairo: Darun Nahdhah al'Arabiyah

Sabiq, Sayyid. 2000. Figh Sunnah, Kairo: Dar al Fath Lil 'Ilam al 'Arabi

Zahrah, Muhammad Abu. 1996. AlMilkiyah wa An-Nadhariyah Al-Aqdi wa Syari'ati Islamiyati. Bairut: Darul Fikri al-'Arabi 